\title{
Autologous and Allogenous Antibodies in Lung and Islet Cell Transplantation
}

\author{
Deepak Kumar Nayak', Prathab Balaji Saravanan², Sandhya Bansal', Bashoo Naziruddin ${ }^{3}$ \\ and Thalachallour Mohanakumar ${ }^{1 *}$
}

${ }^{1}$ Norton Thoracic Institute, St. Joseph's Hospital and Medical Center, Phoenix, AZ, USA, ${ }^{2}$ Baylor Research Institute, Dallas, TX, USA, ${ }^{3}$ Baylor Simmons Transplant Institute, Dallas, TX, USA

\section{OPEN ACCESS}

Edited by:

Narinder K. Mehra,

All India Institute Of Medical

Science, India

Reviewed by:

Eric Spierings,

Utrecht University, Netherlands Brian Duncan Tait,

Australian Red Cross Blood

Service, Australia

Dimitri S. Monos,

University of Pennsylvania, USA

*Correspondence:

Thalachallour Mohanakumar

t.m.kumar@dignityhealth.org

Specialty section:

This article was submitted to Alloimmunity and Transplantation,

a section of the journal

Frontiers in Immunology

Received: 05 August 2016 Accepted: 14 December 2016 Published: 23 December 2016

Citation:

Nayak DK, Saravanan PB, Bansal S, Naziruddin $B$ and Mohanakumar $T$ (2016) Autologous and Allogenous

Antibodies in Lung and Islet Cell Transplantation.

Front. Immunol. 7:650. doi: 10.3389/fimmu.2016.00650
The field of organ transplantation has undoubtedly made great strides in recent years. Despite the advances in donor-recipient histocompatibility testing, improvement in transplantation procedures, and development of aggressive immunosuppressive regimens, graft-directed immune responses still pose a major problem to the long-term success of organ transplantation. Elicitation of immune responses detected as antibodies to mismatched donor antigens (alloantibodies) and tissue-restricted self-antigens (autoantibodies) are two major risk factors for the development of graft rejection that ultimately lead to graft failure. In this review, we describe current understanding on genesis and pathogenesis of antibodies in two important clinical scenarios: lung transplantation and transplantation of islet of Langerhans. It is evident that when compared to any other clinical solid organ or cellular transplant, lung and islet transplants are more susceptible to rejection by combination of allo- and autoimmune responses.

Keywords: lung, islet of Langerhans, transplantation, antibody, graft rejection

\section{INTRODUCTION}

Solid organ transplantation is increasingly used as a clinical intervention to compensate for functional loss of an organ and to maintain metabolic homeostasis. This palliative treatment option can extend the lifespan and improve the quality of life for recipients, but outcomes vary depending on which organ is transplanted. Lung transplantation (LTx) can be a life-saving measure for patients with many severe chronic lung diseases, including chronic obstructive pulmonary disease, idiopathic pulmonary fibrosis, cystic fibrosis, alpha-1 antitrypsin deficiency, pulmonary hypertension, interstitial lung disease, and bronchiectasis. Unfortunately, LTx currently has the lowest long-term survival rate compared with survival rates associated with transplantation of other solid organs, its half-life $\left(t_{1 / 2}\right)$ being just 5 years. The primary reason for this low survival rate is chronic rejection, the clinical diagnosis for which is bronchiolitis obliterans syndrome (BOS).

Transplantation is not limited to solid organs. Allogeneic endocrine cell transplantation of islets of Langerhans is a treatment option for patients with autoimmune diabetes mellitus [i.e., type 1 diabetes (T1D)]. Transplantation of these cells is a replacement therapy that augments production of endogenous insulin. Islet cells are often isolated from multiple cadaveric donors and recipients require a continuous immunosuppressive therapy. However, long-term sustained normoglycemia is exceedingly difficult to achieve from islet transplantation; the mechanisms that lead to destruction of the islet allografts will be discussed in this review. Autologous islet transplantation-which 
also aims to restore endocrine pancreatic function after total pancreatectomy-is not as susceptible to rejection and therefore will not be discussed in this review. Because transplantation depends upon available donor organs and cells, genetic mismatches between donor and recipient become the focal points of the recipient's immunologic responses. Resultant $\mathrm{T}$ cell and antibody $(\mathrm{Ab})$ responses have been known to influence, often negatively, both short- and long-term functioning of transplanted allografts, and such incidences frequently portend the unfavorable consequences of graft loss (i.e., rejection).

In this review, we describe the spectrum of $\mathrm{Ab}$ responses observed in LTx and in transplantation of islets of Langerhans. LTx, whether unilateral or bilateral, involves surgical replacement of a diseased organ with normal and functioning lungs procured from a cadaveric donor. By contrast, allogeneic islet transplantation involves intrahepatic delivery of donor-isolated islet cells that supplement existing islet cells and insulin production resulting in normoglycemia. With recent increases in the prevalence of chronic obstructive pulmonary disease, cystic fibrosis, and T1D, the demand for transplantable lungs and pancreatic islets has increased. Since 2014, nearly 60,000 LTx procedures have been performed worldwide (both lungs-only and combined heart-lung transplantation; International Society for Heart and Lung Transplantation, ${ }^{1}$ accessed on July 25, 2016). As of 2012, approximately 1,400 islet cell transplantations have been recorded (Collaborative Islet Transplant Registry, ${ }^{2}$ accessed on July 25, 2016). Additionally, combined transplantation of lungs and pancreatic islets is an effective treatment option to restore respiratory and pancreatic insufficiency in terminal cystic fibrosis (1). The global need for organ transplantation is rising steadily with more prospective transplant recipients added to active waitlists (both first-time transplantation and re-transplantation due to graft failure). Concurrently, an acute shortage persists on the availability of transplantable organs (Organ Procurement and Transplantation Network ${ }^{3}$ ).

\section{ANTIBODIES IN LTX}

Histocompatibility studies originated from the need to decipher mechanisms of graft rejection; these studies ultimately led to the identification of major histocompatibility complex (MHC) proteins. The human counterpart of MHC is the human leukocyte antigen (HLA) system. From an immunologic perspective, the revelation of HLA was critical to the understanding of immune responses-not only as they affect graft rejection, but also how they impact infectious disease, autoimmunity, and tumor biology. Notwithstanding the antigen presentation via peptide-MHC complexes that is central to $\mathrm{T}$ cell immune recognition and responses, MHC represents the bulk of steady state expression of surface proteins (up to 70,000 molecules per cell) (2). Class I MHC is ubiquitously expressed on every nucleated cell, whereas class II MHC is preferentially expressed on professional

${ }^{1}$ www.ishlt.org/registries/.

${ }^{2}$ www.citregistry.org/.

${ }^{3}$ https://optn.transplant.hrsa.gov. antigen-presenting cells (e.g., dendritic cells, macrophages, and B cells).

With more than 200 loci identified, the polygenic nature of HLA combined with high allelic polymorphism ( $>14,000$ alleles for HLA class I and II combined, ${ }^{4}$ assessed on November 17, 2016) confers great diversity to HLA molecules (3-6). Furthermore, codominant expression of HLA allows for simultaneous expression of both paternal and maternal HLA haplotypes, which further increases the diversity of the HLA repertoire expressed in a given individual. Because of the high preponderance of HLA class I on every type of cell (i.e., ciliated, non-ciliated, and secretory epithelial cells; endothelial cells; basal cells; and connective tissue) and HLA class II on resident antigen-presenting cells (i.e., lung-resident macrophages and dendritic cells) and $B$ cells, mismatched donor HLA molecules are easily recognized and quickly targeted by the recipient's immune system after transplantation.

Although graft failure was long suspected to be a result of immunological complications, the host-adaptive immune response to MHC antigens wasn't confirmed until 1956, when immunization of malignant cells in mice induced de novo Abs against $\mathrm{MHC}$ molecules (7). In a clinical setting, the association of preexisting HLA Abs with graft failure was witnessed when a large number of kidney transplant recipients who experienced acute graft rejection had donor HLA Abs (i.e., positive crossmatch), whereas recipients who lacked anti-HLA (i.e., negative crossmatch) had significantly higher graft survival $(8,9)$. Since these landmark studies, preexisting and de novo donor-specific antibodies (DSA) to mismatched HLA have generated a tremendous amount of clinical interest and have been widely applied in the study of all solid organ transplantation (10). The posttransplant development of de novo DSA was first documented following LTx in 2002 (11). Since then, a strong clinical association of de novo DSA with acute and chronic lung allograft rejection has been confirmed by many independent studies (12-20). Significantly, an association between the extents of donor-recipient HLA mismatches and incidence of chronic rejection (i.e., BOS) has been established (21) indicating a role for anti-HLA immune responses in the post-LTx acceptance and performance of lung allografts.

The pathogenicity of MHC Abs has been demonstrated in our laboratory using a mouse model of obliterative airway disease (OAD), in which ligation of MHC by antibodies led to OAD and lung-restricted autoimmunity $(22,23)$. In this model, exogenous delivery of anti-MHC class I or anti-MHC class II to the lung microenvironment induced small airway occlusion and fibrosis, creating pathologic lesions similar to those observed in humans with chronic lung graft rejection. While the Ab repertoire associated with lung graft rejection is not fully characterized, de novo anti-HLA class I and II titers, even when non-persistent, significantly predispose to chronic rejection $(11,15,17,19,24-28)$. The alloimmune priming of HLA reactive $B$ cells is believed to trigger loss of self-tolerance and development of cellular and humoral autoimmunity $(26,29)$. Owing to clinical significance, a number of transplant centers now routinely screen prospective LTx

${ }^{4}$ https://www.ebi.ac.uk/ipd/imgt/hla/stats.html. 
recipients for preexisting DSA for an immediate pretransplant desensitization and monitor for de novo DSA during posttransplant period.

In addition to HLA, several non-HLA molecules have been targeted by immune responses after allogeneic transplantation, which can influence post-LTx outcomes. Abs to MHC class I chain A (MICA) were reported to develop after DSA and were significantly correlated with BOS development (30). Abs to mismatched HLA or MICA are suspected to induce immune responses to various tissue-restricted self-antigens $(26,30)$. Development of Abs to filamentous self-proteins such as Collagen $\mathrm{V}(\mathrm{Col} \mathrm{V})$ and $\mathrm{K}$-alpha1 tubulin $(\mathrm{K} \alpha 1 \mathrm{~T})$ have been studied in LTx recipients with great interest (31), and in experimental mice with OAD $(22,23)$. Col V forms the core component of the fibrillar extracellular matrix (ECM) in the lungs, and K $\alpha 1 \mathrm{~T}$ is a cytoskeletal protein involved in intracellular locomotion. Preexisting anti-Col $\mathrm{V}$ and anti-K $\alpha 1 \mathrm{~T}$ have also been associated with primary lung graft dysfunction $(32,33)$, which predisposes LTx recipients to development of both acute rejection (34) and BOS (35). Furthermore, role of anti-Col V and anti-K $\alpha 1 \mathrm{~T}$ has been demonstrated in murine orthotopic LTx model where exogenous $\mathrm{Ab}$ administration disrupted an established lung graft tolerance resulting in fibrotic lesions in small airways and elicited lungdirected cellular autoimmunity (36). Despite the current focus on these two tissue-associated self-antigens (i.e., Col V and K $\alpha 1 \mathrm{~T}$ ) as a measure of lung-restricted autoimmunity, it is likely that a larger antigenic repertoire participates in lung graft-directed immune responses and rejection. Further analysis of these putative antigens may help delineate the pathogenic processes and facilitate development of new therapeutic strategies.

\section{Intricacy of B Cell Targets}

Terasaki proposed a "humoral theory" to explain the basis of Abs influencing allograft rejection (37). This theory, formulated after in-depth analysis of kidney, heart, lung, and liver transplants, states that detection of graft-specific Abs is a reliable measure of humoral sensitization and an early indicator of graft rejection. The humoral theory gained credence when anti-donor humoral response was established to be the major factor in hyperacute and chronic graft rejection $(10,38)$. B cell sensitization against mismatched donor HLA may readily occur as they are non-self proteins and, by virtue of their cell-surface expression, are amenable to B cells. Further, an indirect antigen presentation pathway has been established in which a recipient's antigenpresenting cells acquire the donor antigens, activating antigenspecific CD4 $\mathrm{T}$ cells that provide necessary costimulation for B cell priming (39). An intercellular antigen transfer has also been described in LTx, wherein recipient's antigen-presenting cells acquire and cross-present donor antigens via a "semidirect" pathway (40).

The generation of $\mathrm{Ab}$ to sub-surface non-HLA antigens (including various tissue-restricted self-antigens) is poorly understood. Col V is an important component of heterotopic collagen fibers, as it initiates the fibril assembly by serving as a nucleator to Collagen I and regulates the number and length of fibrils (41). Col V is a minor component (constituting nearly $2-5 \%$ of total collagen in most tissue) and remains buried in the healthy collagen fibers, while K $\alpha 1 \mathrm{~T}$ is a polymerized cytoskeletal protein of the microtubule. Given their intracellular sequestra-

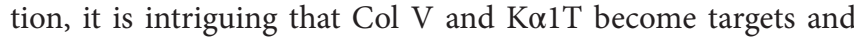
driving forces for immunopathogenesis of lung allograft rejection. In order for this self-antigen-directed reactivity to proceed, two significant immunologic requisites must be fulfilled: (1) Col $\mathrm{V}$ and K $\alpha 1 \mathrm{~T}$ must be available to the immune system since B cell receptors can recognize native or linear epitopes, and the buried or "cryptic" antigens (i.e., Col V and K $\alpha 1 \mathrm{~T}$ ) must be accessible to the circulating B cells during post-LTx sensitization; and (2) the repertoire of $\mathrm{Col} V$ and $\mathrm{K} \alpha 1 \mathrm{~T}$ specific $\mathrm{B}$ cells must be intact and functional.

Mechanisms and modality of how the sequestered lungrestricted antigens may become bioavailable has generated significant clinical interests. Metalloproteases produced during transplant-related ischemic reperfusion injury to the lungs structurally impair fiber integrity and strip the collagen fibers, thereby exposing the core Col V fibers $(42,43)$. In addition, fragments of $\mathrm{Col} \mathrm{V}$ are released into bronchoalveolar lavage fluid after allogeneic LTx (44). It is possible that during this immunologic assault (which may result in cell death), cytoskeletal components may become available for B cell priming. Nevertheless, the notion of a circulating pool of $\mathrm{Col} V$ and $\mathrm{K} \alpha 1 \mathrm{~T}$ reactive $\mathrm{B}$ cells requires thoughtful analysis and experimentation. Notwithstanding the ubiquitous expression of $\mathrm{Col} \mathrm{V}$ and $\mathrm{K} \alpha 1 \mathrm{~T}$, lack of a deletional tolerance may introduce risk of autoimmunity. The possible escape of Col V-and K $\alpha 1 \mathrm{~T}$-reactive B cells may be due to an incomplete clonal deletion, or the immune response directed toward altered/neo-epitopes on $\mathrm{Col} \mathrm{V}$ and $\mathrm{K} \alpha 1 \mathrm{~T}$ generated by posttranscriptional modifications. Recent study strongly suggests that the breakdown of peripheral tolerance via $\mathrm{T}$ regulatory cell populations may affect the development of immune responses to these fibrillar proteins (45). Nonetheless, clonal tolerance has been successfully achieved in a rat LTx model, in which oral administration of $\mathrm{Col} \mathrm{V}$ induced protection from chronic rejection $(46,47)$.

While several possible routes may exist by which donor antigens become available to immune priming, our laboratory and others' have recently demonstrated a long-term persistence of donor-derived alveolar macrophage (AM) in transplanted lungs $(48,49)$. The donor AMs act as a reservoir of donor HLA and are available for stimulating graft-infiltrating B cells. We have also shown that mismatched MHC present on AM is sufficient to elicit anti-donor T cells and Abs. Therefore, the donor AM may initiate and/or contribute to the post-LTx DSA responses. At the instance of a matched HLA class II allele between donor and recipient, donor AMs can participate in direct presentation of endogenous antigens (donor-derived) to the recipient's CD4 T cells.

In order to define the spread of alloantigenic immune responses in to tissue-restricted autoimmune response, we recently characterized exosomes isolated from serum samples from LTx recipients (50). Exosomes are membrane-bound nano-vesicles involved in cell-to-cell communication. In our study, exosomes from patients with acute rejection and with BOS contained donor HLA, Col V and K $\alpha 1 \mathrm{~T}$, and various immunostimulatory microRNAs. Exosomes from stable LTx recipients, however,

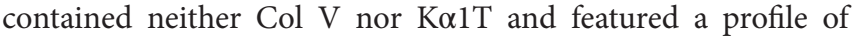


immunoregulatoy microRNAs. It is hypothesized that exosomes in patients with graft rejection are immunogenic and that these exosomes can essentially traffic and deliver their antigenic cargo toward priming of allogeneic donor HLA and lung-restricted autoantigen specific of CD4 T cells (50). The role of exosomes has also been recognized in other solid organ transplantations (51). Whether or not exosomes participate in the antigen presentation by semidirect pathway has not been established, and their contribution to the indirect and direct pathways of antigen presentations remains to be validated.

Analysis of ECM, as a potential source of lung-restricted selfantigens, in small airway inflammation and fibrosis associated with BOS is unconventional. Biochemically, ECM is a complex adduct of glycoproteins, collagens, and polysaccharides and is responsible for homeostatic maintenance of the lungs, including their development, maturation, and post-injury tissue repair $(52,53)$. In patients with fibrotic lung diseases or who develop BOS after LTx, aberrant ECM deposition leads to permanent tissue scarring. An alloimmune reaction directed at the lung graft generates "redox hotspots" with surplus reactive oxygen species. Redox reactions in the lungs are known to modulate signaling and composition of ECM (54), pericellular localization, and extracellular focal plaque formation (55). The inflammatory nature of ECM, particularly with regards to ECM-infiltrating immune cells and composition of the fibrotic scars, may indicate the role of $\mathrm{ECM}$ as an antigen reservoir and initiator of inflammation that prompts lung-directed autoimmune responses.

With regards to small airway epithelial cells, club cells may play an important role in the elicitation and/or amplification of lung graft-directed immune responses. Club cell secretory protein (CCSP) is an important component of the pulmonary surfactant that has an anti-inflammatory function (56-60). A significant reduction in bronchoalveolar CCSP and club cells has been reported in LTx recipients who develop BOS compared to stable LTx recipients (61). These results suggest that declining CCSP may augment both the innate and adaptive immune responses that lead to lung allograft rejection.

\section{Pathogenesis}

The tenets of Terasaki's humoral theory $(10,37,38)$ on the primary role of HLA Abs in solid organ rejection remain generally undisputed, and the development of Abs and their correlation with lung graft rejection has been increasingly reported across transplant centers. Because adaptive cellular and humoral effectors work in tandem in the elicitation of graft-directed immune responses, it is difficult to ascribe a dominant role for one over the other. With respect to immunologic factors associated with allograft rejection, Terasaki and Cai suggested that: (1) Abs play a causative role in the pathogenesis of graft rejection and (2) acute cellular rejection (ACR) can be of humoral origin (38).

Antibody-mediated rejection (AMR) of a lung graft results in three primary, interdependent manifestations: (1) hyperacute rejection, (2) acute humoral rejection, and (3) chronic lung allograft dysfunction (CLAD). Although AMR lesions are well defined in renal and cardiac allografts, the criteria for assessment of lung AMR are continuously changing based on varying immunopathology observed in pulmonary biopsies. The recent
International Society for Heart and Lung Transplantation grading criteria for evaluating lung graft rejection define pulmonary AMR as presence of donor-HLA-specific Abs and characteristic lung histology that may or may not be accompanied by complement deposition in the graft (62). Furthermore, AMR may persist subclinically-that is, without being detected. Occurrence of preformed, sometimes-low-titer Abs to donor-HLA, Col V or K $\alpha 1 \mathrm{~T}$ pre-LTx have been shown to increase risk of graft rejection $(33,63)$. Delivery of exogenous anti-Col V and anti-K $\alpha 1 \mathrm{~T}$ produced AMR in experimental murine LTx $(32,64)$. ACR is a common but reversible immune reaction, with characteristic perivascular or peribronchiolar mononuclear infiltrations. AMR, on the other hand, is difficult to diagnose and may accompany local activation of complements caused by DSA (65-67).

Higher frequency and high grade of AMR are risk factors for development of HLA Abs and BOS $(34,68)$, but AMR exhibits a strong association with de novo development of anti-HLA, significantly increasing the risk of BOS (24). BOS continues to be the major cause of posttransplant morbidity and mortality, affecting approximately 50\% of patients with transplanted lungs within 5 years of LTx (69). It clinically manifests with progressive, irreversible loss of respiratory function ( $>20 \%$ of baseline) that is unresponsive to any immunosuppressive regimen (70). A large body of work has established a strong humoral link that predisposes for development of BOS after LTx. DSA directed to MHC class I and II proteins, even when detected only transiently, poses significant and independent risks for BOS development and influences its onset kinetics, severity, and mortality $(11,15,17,19,24-28,71)$.

In addition to BOS, restrictive allograft syndrome (RAS) has been recently described as another form of CLAD after human LTx (72). RAS is an airway-restrictive phenotype and is more aggressive than BOS, with median survival of just 6-18 months after diagnosis (73-76). The alloimmune priming of donor-HLA reactive $B$ cells is believed to trigger loss of self-tolerance and intermolecular epitope spreading, eliciting cellular and humoral responses directed to $\mathrm{Col} \mathrm{V}$ and $\mathrm{K} \alpha 1 \mathrm{~T}$. Therefore, a functional interplay has been proposed in which donor-directed alloimmunity leads to development of tissue-restricted autoimmunity to self-antigens $(26,29,77)$.

The immunodominant role of DSA in chronic rejection has been recognized by three distinct observations: (1) de novo DSA is associated with recurrent and high-grade cellular rejection and lymphocytic bronchiolitis $(11,15),(2)$ development of DSA

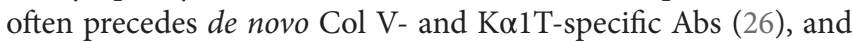
(3) depletion of the circulating Abs by Ab-directed therapy offers protection from BOS with a lower hazard ratio and enhanced pulmonary function $(25,27,78-80)$. Preexisting Abs to Col V and $\mathrm{K} \alpha 1 \mathrm{~T}$ have been found in different terminal lung diseases preLTx, and such pretransplant autoantibodies were significantly correlated with poor outcomes, including development of DSA and $\operatorname{BOS}(33,81)$. Moreover, the absence of preexisting Abs to lung self-antigens was correlated with freedom from de novo $\mathrm{MHC}$ class I and class II DSA and with lower incidence of BOS (33). Preformed antibodies to lung-restricted self-antigens without measurable DSA have also been associated with BOS development after human LTx (24). In summary, the current consensus is 
that both DSA and Abs to lung-restricted self-antigens (whether preformed or de novo) are significant risk factors for all forms of lung allograft rejection and limit both short- and long-term success of LTx.

\section{Diagnosis}

Sensitive detection and measurement of graft-specific Abs have been closely linked with the evolution of allogeneic organ transplantation, often serving as a designation of success in solid organ transplantation. With outcomes being dependent on the extent of antigenic mismatches between donor and recipient, optimization of matching strategies has been the subject of much discussion. A consensus guideline has been formulated for $\mathrm{Ab}$ testing in transplantation (82). Crossmatching was an early test in which recipient's serum was mixed with donor's cells to detect presence of anti-donor Abs. A negative crossmatch-first applied in renal transplantation-was effective in minimizing graft failure (9). The development of the complement-dependent cytotoxicity test utilized complement fixation and mixing of donor lymphocytes with recipient's serum in the presence of complement. This assay was further refined when antiglobulin was added to augment the reaction (83).

More recently, however, flow cytometry has been the test of choice to define crossmatch compatibility, given its high sensitivity. A shortcoming of crossmatching is the amount of time it takes-it was difficult to perform prospectively and it increased cold ischemic time of the organ. Currently, a virtual crossmatch is preferred, especially for lung and heart transplantation procedures. The development of the "HLA/Teraski plate" was a crucial step in the commercialization of assay reagents, as it enabled testing for presence and specificity of panel-reactive antibodies (PRAs). Recently, solid-phase immune assays such as FlowPRA (OneLambda, Canoga Park, CA, USA), LABScreen (OneLambda, Canoga Park, CA, USA) and Lifecodes LifeScreen (Immucor, Peachtree Corners, GA, USA) were developed. FlowPRA is a flow cytometry-based immunoassay for rapid detection of HLA class I and class II Abs in human serum. Using a unique set of recombinant HLA protein adsorbed fluorescent microbeads binding of specific Abs in serum is detected by flow cytometry. LABScreen and LifeScreen, on the other hand, allow precise determination of allelic HLA and/or MICA on a Luminex (Luminex Corporation, Austin, TX, USA) platform. Currently, assays such as LABscreen and FlowPRA are standard and are routinely conducted for testing of PRAs at HLA laboratories. These assays can successfully assign antigenic specificities to perform virtual crossmatching.

In stark contrast to the advancements in immunologic detection of HLA Abs, progression of methods to identify and characterize Abs to tissue-restricted self-antigens is in its infancy. The diversity of tissue-restricted self-antigens involved in allograft rejection is still being investigated, and there are no validated kits commercially available for detecting immune responses to self-antigens. In addition, a possibility of low titer circulating Abs (below detection limit) as the graft undergoing rejection may already sequester them further complicates the detection issue. A solid-phase protein microarray has been employed to screen targets of humoral autoimmunity following LTx (84).
Given the nature of nuanced B cell antigenic determinants (i.e., conformational vs linear; continuous vs discontinuous), cellular localization (i.e., surface-bound, cytosolic, or nuclear), and posttranscriptional modifications, the results obtained from solid-phase assays are limited in their capacity to gauge the spread of humoral autoimmunity. This prevents full realization of the $\mathrm{Ab}$ repertoire and limits researchers' ability to identify novel targets. Currently, home-grown enzyme-linked immunosorbent assays are the most commonly used procedures for detecting Abs to various tissue-restricted self-antigens $(31,32)$.

\section{CLINICAL PANCREATIC ISLET TRANSPLANTATION}

Transplantation of whole pancreas or isolated pancreatic islets are two effective treatment options for brittle (i.e., severe) T1D patients, as both procedures replace the depleted $\beta$-cell mass lost due to autoimmunity. Islet transplantation has the advantage of being a minimally invasive procedure compared to transplantation of pancreas. Most of T1D patients receive exogenous insulin therapy to control blood glucose levels, but this often results in severe and recurrent of hypoglycemia (85). Many patients who undergo islet transplantation achieve normoglycemia and experience freedom from the life-threatening consequences of severe hypoglycemic episodes. Despite significant advances in the islet isolation protocol, islets isolated from more than one donor pancreas are often required to achieve insulin-independent status (86), and a majority of islet transplant recipients return to some form of exogenous insulin usage within a few years of transplantation due to chronic rejection (87).

According to the Collaborative Islet Transplant Registry (See text footnote 2) data collected from the islet transplant centers around the world indicate 1 - and 5-year insulin-independence rates after final islet infusion at $50 \%$ and $23 \%$, respectively. Majority of the procedures performed in North America are islet transplant alone where as a higher number of procedures performed at European centers are simultaneous islet-kidney allograft (SIK) transplantation or islet after kidney allograft (IAK) transplantation. The SIK/IAK rate in North America is $10 \%$ were as that in European centers are $>35 \%$. A small number of islets after LTx have been successfully performed at the GRAGIL (Groupe Rhin-Rhône-Alpes-Genève pour la Transplantation d'Ilots de Langerhans) consortium (1). This combined transplantation was particularly beneficial for patients with end-stage cystic fibrosis and severe cystic fibrosis-related diabetes. Long-term follow-up on transplant recipients resulted in persistent improvement of glycemic control with normalized glycated hemoglobin $\left(\mathrm{HbA}_{\mathrm{lc}}\right)$ in conjunction with significant $(50 \%)$ reduction in the daily exogenous insulin requirement. The normoglycemia was durable and was preserved for a durable period of 15 years in these lung-islet combined transplant recipients.

Multiple factors contribute to loss of islet grafts, including poor islet quality, posttransplant inflammation, immunosuppressive drug-induced toxicity, recurrent autoimmunity, $\beta$-cell exhaustion, and alloimmune responses (88). Primary causes of islet allograft rejection are thought to be incidences of $\beta$-cell 
directed autoimmunity in combination with the alloimmune response to multiple mismatched HLA antigens that significantly impact long-term islet cell function.

\section{Alloimmunity against Islet Grafts}

Introduction of allogeneic tissue into the body during solid organ or cellular transplantation is known to produce de novo anti-HLA, which plays a major role in acute and/or chronic graft failure. Rejection due to alloimmunity after islet transplantation is mainly due to the Abs against donor-specific HLA class I and II molecules $(89,90)$. Moreover, the requirement of multiple islet infusions to achieve insulin independence exposes transplant recipients to an unusually high number of HLA mismatches, resulting in elevated risk for a broader spectrum of donor-specific HLA Abs (88). Our group researched a possible role for HLA Abs in the rejection of islet allografts (91). This report was followed by a comprehensive analysis of both cellular and humoral responses against donor-specific antigens in seven islet transplant recipients, and a clear association of flow cytometry-detected and immunospot-detected T cells with islet graft failure was revealed (92). Of these seven patients, three with positive donor-specific responses rejected islet allografts, either acutely or chronically. A concurrent report by Rickels et al. reported islet graft failure in two of six patients with detectable HLA class I and II antibodies (93). Cardani et al. analyzed HLA sensitization in 66 patients who underwent islet transplantation at a single center between 1985 and 2006 and reported no significant correlation between positive PRA and islet graft transplantation outcome (94). However, loss of islet graft function was associated with positive PRA after immunosuppression tapering or infection. The study by Cardani et al. also revealed that $24 \%$ patients developed PRA after immunosuppression was discontinued.

The Edmonton group revealed its findings on the role of anti-donor HLA in the islet allograft rejection in a large patient cohort, screening posttransplant HLA Abs in 98 patients. In their cohort, 29 patients (30\%) developed DSA, including 23 recipients (23.5\%) who developed DSA while still on immunosuppression. Ten of the fourteen patients $(71 \%)$ who discontinued immunosuppression developed extensive amounts of PRA. This report documented posttransplant HLA sensitization among patients who had negative PRA prior to transplantation. Importantly, the fasting C-peptide, which is an indicator of islet graft function, was significantly lower in sensitized recipients compared to non-sensitized recipients (95). Another study showed that pretransplant detection of PRA to MHC class I and II (>15\%) among recipients was associated with increased need for insulin post-transplant (96).

The Collaborative Islet Transplant Registry offered a comprehensive analysis of 308 patients who received islet transplantation at different centers between 1999 and 2008. They found that HLA class I sensitization both pre- and posttransplant was correlated with islet graft failure. Unlike any other type of organ transplantation, allogeneic islet recipients could be exposed to a total of 9-25 HLA class I and II antigen mismatches. This extraordinarily high number of mismatches was likely due to the multiple
HLA-mismatched pancreas donors used for islet isolation, and also possibly the result of increased risk of patients receiving any future transplants (88). A significant increase in the level of HLA Abs was seen, even when patients adhered to an immunosuppression regimen. It would be beneficial if islet transplants could be performed with single-donor islet infusion, as it would minimize the risk of broad sensitization.

Despite clinical studies reporting a possible association between HLA sensitization and islet graft failure, causality has still not been definitively established. Previous in vivo studies have indicated an association between DSA and islet transplantation survival. Using a congenic rat islet transplant model, Bittscheidt and colleagues have reported that graft survival was significantly influenced by the degree of donor-recipient MHC matching as well as recipient presensitization (97).

Other reports have shown that the presence of pretransplant autoreactive T cells and de novo donor-specific cytotoxic CD4 T cells resulted in poor outcomes after islet transplantation $(92,98$, 99). In fact, the preformed auto- and alloreactive Abs were considered to be negative indicators for survival of the islet graft (96, $98,100)$. Thus, the adaptive immune system plays essential role in long-term islet graft survival and influences clinical outcomes. The allosensitization triggered by donor antigens likely elicits the interferon- $\gamma$ - and interleukin (IL)-2-mediated $\mathrm{T}$ helper 1 response, which is destructive for the function of the transplanted islets (92). An in vitro study of mixed islet leukocyte reaction by Bouwman et al. showed induction of direct $\mathrm{T}$ cell response with augmented responses in cases with two or more mismatches of HLA class II (101).

A recent contrasting report showed that $11 / 18$ islet transplant recipients $(61.1 \%)$ had preexisting anti-HLA, including 6 patients (33\%) who developed de novo DSA against the HLA of the transplanted islets (90). Remarkably, no significant association existed between the newly developed DSA after islet transplantation and clinical characteristics such as recipient gender, age, number of post-transplant infections, HLA class I/II eplet mismatch, and immunosuppression protocol. Furthermore, the de novo DSA was not associated with reduced graft survival or function. Interestingly, the newly formed posttransplant anti-HLA class II Abs were related to the Predicted Indirectly Recognizable HLA Epitopes (PIRCHE-II ${ }^{5}$ ), specific to the T helper epitopes.

Long-term survival of an allogeneic islet transplant faces a greater challenge than solid organ or other cellular transplants due to the preexisting islet-specific autoimmunity and the likely scenario of multiple HLA-mismatched islet infusions. In a recent analysis of 59 consecutive islet transplant recipients, 39 (66\%) experienced de novo titer increase in both DSA and autoantibodies (96). Patients with increased Ab titers had significantly lower graft survival. Furthermore, newly developed DSA was associated with MHC class II (HLA-DR) mismatches and preexisting PRA (96).

The expression of MHC class II in the endocrine tissue of freshly isolated pancreatic islets is nearly undetectable. However,

${ }^{5}$ http://company.pirche.org/. 
posttransplant infection or the presence of proinflammatory cytokines can induce the expression of MHC class II. Such induced expression of MHC class II has been demonstrated in vitro and has been associated with development of donor-specific HLA class II Ab production after islet transplantation (91).

\section{Autoimmunity against Islet Grafts}

Because pancreatic islet transplantation is often performed in patients with T1D, the existence of preformed autoantibodies against major islet-specific antigens is an inherent issue for most recipients. Autoantibodies in the circulation are formed during the pathogenesis of T1D prior to islet transplantation. Autoantibodies against pancreatic islets that are deemed clinically significant include anti-glutamate decarboxylase 65 (GAD65), anti-insulin autoantibody, anti-zinc transporter ZnT8, anti-islet cell autoantibody, and anti-tyrosine phosphatase autoantibody (IA-2) (102). Some of the earlier reports of posttransplant immune responses in islet transplant recipients suggested that no correlation existed between preexisting autoantibodies and islet graft failure $(96,98)$. Similar claims were made about the role of autoantibodies in clinical outcomes of whole pancreas transplants (103). However, preformed autoantibodies in islet recipients have indeed been associated with graft failure compared with recipients who did not have autoantibodies (104). Compared to preformed autoantibodies, the elevated recurrences of autoantibodies specific to ZnT8A, GAD65, and IA-2 in the posttransplant period were predictive of graft failure in islet transplantation (96) and foretold an $80 \%$ chance of graft failure in transplanted whole pancreas (105). In spite of the early notion of a non-association between preexisting autoantibodies and graft loss, analysis of these autoantibodies may be clinically useful in helping health practitioners anticipate recurrences of autoimmune graft rejection. A number of factors may affect reappearance of autoantibody, for example, suboptimal immunosuppression protocols that include CD25 antagonism or inhibition of mechanistic target of rapamycin (mTOR) by rapamycin. Antithymocyte globulin (ATG) and mycophenolate mofetil (MMF), meanwhile, decrease the risk of autoantibody recurrence (96).

An early study considered seven islet allograft recipients to determine the significance of autoreactivity in islet transplant outcomes (106). In this study, three out of seven recipients under ATG induction immunosuppression retained comprehensive islet function more than 1 year post-transplant, with less autoreactivity and with no alloreactivities. The remaining four patients received no ATG in their immunosuppression treatment. Of these, three patients lost islet function within 3 weeks, and one patient demonstrated hyper-autoreactivity without alloreactivity and experienced a delayed loss of islet function around 33 weeks, with recurrence of autoimmunity (106). This group later studied the incidence of allo- and autoimmunity in 29 islet transplant recipients 1 year after islet transplantation. Repeat analysis included modification in the immunosuppression regimen. ATG was a part of induction, and tacrolimus with MMF were included in the maintenance immunosuppression protocol. The outcomes of this study demonstrated that pre- and posttransplant autoimmunity were associated with delayed insulin non-requirement and autoimmunity was directly proportional to the recipients' circulating C-peptide 1 year post-transplant. Moreover, seven out of eight recipients who had no history of pretransplant autoreactivity achieved insulin independence while none of the four recipients who had preformed autoreactivity, predominantly against GAD and IA-2, achieved insulin independence (107). These analyses suggest that including ATG in the induction immunosuppression may help control autoreactivity and improve islet graft function.

The association between a recipient's pre- and posttransplant autoreactivity and clinical outcomes are often highly variable from center to center. A previous report (106) asserted that no correlation exists between recipients' autoimmunity and graft function posttransplant, but others have stated that $60 \%$ of islet transplantation recipients with fewer autoreactive circulating GAD65 $\mathrm{T}$ cells achieved long-term insulin independence, whereas the $40 \%$ of patients with elevated levels of autoreactive GAD65-specific $\mathrm{T}$ cells producing proinflammatory cytokines and did not achieve long-term insulin independence (108). The findings of Chujo et al. are supported by another report, in which pretransplant GAD65 and IA-2 autoreactive T cells affected the 1-year insulin-independence rate of alloislet transplant recipients (107).

Allogeneic graft rejection and autoimmune recurrence make a critical contribution to long-term outcomes after islet transplantation, and CD4+ and CD8+ T cells are vital in the pathogenesis of graft rejection. Moreover, T1D recipients have an increase in autoreactive memory $\mathrm{T}$ cells (109). Donor-specific MHC molecules likewise play an important role in activation of immunogenic $\mathrm{T}$ cells in the recipients, affecting islet graft outcomes. Huurman et al. analyzed islet transplantation recipients' cellular responses to donor-specific MHC class II antigens and measured the expansion of alloreactive CD4+ T cells by ${ }^{3} \mathrm{H}$-thymidine incorporation (110). They also measured release of pro- and anti-inflammatory cytokines in the culture supernatant in vitro. Recipients who achieved long-term insulin independence expressed greater IL-10 release and regulatory T cells compared to recipients with failed allografts, who showed more IL-2 release in the supernatant (110).

Autoreactive CD8+ $\mathrm{T}$ cells are thought to play an active role in the destruction of alloislet graft. Memory autoreactive T cells have a longer half-life, are preserved in the circulation for a long time and expand after exposure to the specific autoantigens posttransplantation. Velthuis et al. analyzed frequency of CD8+ $\mathrm{T}$ cells in T1D patients and islet transplant recipients and demonstrated that $\mathrm{T}$ cells reacting to insulin and pre-proinsulin epitopes increased after transplantation (111). Further, the presence of some alloreactive CD8+ T cells possibly due to donor/recipient MHC mismatch induced expansion of cytotoxic T cells causing acute islet graft rejection (99).

\section{Immunosuppression in Islet Transplantation}

Understanding the role of islet-specific alloimmune responses and autoimmunity in islet graft function has been useful in designing effective immunosuppression regimens that can control graft failure. Most immunosuppression drugs commonly used 
in whole organ transplantation are either lethal to transplanted islets or induce diabetes in the recipients. For recipients of islet transplantations, azathioprine, cyclosporine, and corticosteroids are usually included in the immunosuppression regimen in the immediate posttransplant period. Most islet transplants are performed after renal or simultaneously with renal transplantation. Application of these immunosuppression regimens has produced variable posttransplant outcomes in islet transplantation (112-114). Cyclosporine sparing immunosuppression is preferred based on several in vitro studies that have documented its $\beta$-cell toxicity $(112,115,116)$.

The outstanding posttransplant result achieved with the Edmonton protocol (i.e., seven out of seven patients became insulin-independent) was partly due to a modified immunosuppression regimen, which included no steroids, and included induction with daclizumab and maintenance with low-dose tacrolimus and sirolimus (117). Impaired graft function and $\beta$-cell proliferation were reported with sirolimus $(118,119)$; however, no clinically significant adverse effects or decrease in islet engraftment were reported (120). In spite of its diabetogenic property, inclusion of low-dose tacrolimus in the immunosuppression maintenance protocol effectively improved short-term islet graft function (121). For long-term islet graft function, however, the Edmonton protocol was not effective. Among 47 patients who achieved insulin independence, only four (8.5\%) retained the insulin-independent status at 5 years (122).

Recent improvement in the immunosuppression protocol has significantly enhanced the clinical islet transplant outcomes as illustrated in Table 1. Long-term islet transplant outcomes were improved with the use of humanized anti-CD3 Ab (OKT3 $\gamma 1$ Ala-Ala) for induction that depletes mature $\mathrm{T}$ cells followed by administration of calcineurin and mTOR inhibitors. The same group later effectively used $\mathrm{T}$ cell depletion with ATG along with antitumor necrosis factor $\alpha$ in the induction regimen and achieved superior long-term insulin independence in 50\% (4/8) of the recipients $(123,124)$.
The Clinical Islet Transplantation Consortium ${ }^{6}$ recently reported encouraging results in 48 patients who underwent islet transplantation. All 48 T1D patients experienced severe hypoglycemic episodes and impaired awareness of hypoglycemia pretransplant, and all maintained a regimen of ATG or basiliximab for induction and sirolimus with low-dose tacrolimus for immunosuppressive maintenance (85). In this study, the primary end point fixed was the accomplishment of $\mathrm{HbA}_{\mathrm{lc}}<7.0 \%(53 \mathrm{mmol} /$ $\mathrm{mol}$ ) at 1 year and freedom from severe hypoglycemic episodes from day 28 to day 365 after initial transplant. The primary end point was effectively met by $42 / 48$ patients $(87.5 \%)$ at one and by $34 / 48$ patients $(71 \%)$ at two posttransplant years. Hypoglycemia awareness was significantly restored $(p>0.0001)$, with marked improvement in Clarke and HYPO scores in all patients in the study (85).

A major obstacle to successful islet engraftment is the activation of an innate immune response, called "instant blood-mediated inflammatory response" (IBMIR). This reaction is characterized by release of proinflammatory cytokines, infiltration of innate immune cells, and activation of coagulation pathways (130). IBMIR has been documented in all three forms of islet transplantation (i.e., autologous, allogenous, and xenogenous). It is estimated that roughly $50 \%$ of transplanted islets are irreversibly damaged during the peri-transplant period, usually within hours to days. Following islet transplantation, release of proinflammatory cytokines and chemokines has been reported (131). These soluble molecules include tissue factor, high-mobility group protein $\mathrm{B} 1$, cytokines and chemokines such as chemokine (C-C motif) ligand 2, chemokine (C-X-C motif) ligand (CXCL) 12, tumor necrosis factor (TNF) $\alpha$, IL-1 $\beta$, IL-6, and CXCL8/IL-8. Introduction of two anti-inflammatory compounds that inhibit TNF- $\alpha$ (etanercept), IL-1 $\beta$ (anakinra) has been shown to improve islet allograft function (126). However, a direct link between the control of IBMIR and development autoimmune and alloimmune responses has

${ }^{6}$ www.citisletstudy.org.

TABLE 1 | Immunosuppression strategies in clinical pancreatic islet transplantation.

\begin{tabular}{|c|c|c|c|c|c|}
\hline Induction IS & Maintenance IS & No. of recipients & Type of transplant & Il achieved & Year/reference \\
\hline ATG + Bela & Sir + MMF & 5 & ITA & 5 & $2010 /(125)$ \\
\hline$A T G+E f a /$ & Sir + MMF & 5 & ITA & 5 & $2010 /(125)$ \\
\hline$A T G$ + ETA + Ana/ & Tac/MMF & 3 & ITA & 3 & $2011 /(126)$ \\
\hline Dac/ & Tac/Sir & 3 & ITA & 3 & $2011 /(126)$ \\
\hline$A T G$ + Tep or ATG + TCDAb + TNFi & Tac or CsA/Sir or CsA/Sir or Eve & 29 & ITA & 15 & $2012 /(124)$ \\
\hline TCDAb + TNFi & Tac or CsA/Sir or Eve & 20 & ITA & 10 & $2012 /(124)$ \\
\hline TCDAb & Tac or CsA/Sir or Eve & 43 & ITA & N/A & $2012 /(124)$ \\
\hline Dac & Tac or CsA/Sir or Eve & 177 & ITA & 35 & $2012 /(124)$ \\
\hline ATG & Sir & 12 & ITA & 5 & $2014 /(127)$ \\
\hline ATG & Tac + MMF & 48 & ITA & N/A & 2014/(128) \\
\hline ATG or Dac or Bas & Tac or Sir & 38 & SIK/IAK & 4 & $2015 /(129)$ \\
\hline ATG or Bas & $\mathrm{Sir}+\mathrm{Tac}$ & 48 & ITA & 25 & 2016/(85) \\
\hline ATG or Bas & Ste or Tac + Aza & 18 & ITA/SIK/IAL/SILL & 9 & 2016/(90) \\
\hline
\end{tabular}

Ale, alemtuzumab; Ana, anakinra; ATG, antithymocyte globulin; Aza, azathioprine; Bas, basiliximab; Bela, belatacept; CsA, cyclosporine A; Dac, daclizumab; Efa, efalizumab; Eta, etanercept; Eve, everolimus; Exe, exenatide; IAK, islet after kidney transplantation; IAL, islet after lung or liver transplantation; II, insulin independence achieved in no. of patients; Inf, infliximab; IS, immunosuppression; ITA, islet transplantation alone; MMF, mycophenolate mofetil; N/A, not available; SIK, simultaneous islet-kidney transplantation; SILL, simultaneous islet-liver-lung transplantation; Sir, sirolimus; Ste, steroids; Tac, tacrolimus; TCDAb, T cell depleting antibodies; TNFi, tumor necrosis factor- $\alpha$ inhibition. 
not been established in allogenic islet transplantation and will undoubtedly be the focus of future studies.

\section{CONCLUSION}

In this review, we have synthesized the published reports on immune responses to alloantigens encoded by HLA loci and non-HLA tissue-restricted self-antigens in the pathogenesis of graft rejection after human lung and islet transplantation. Much work has been done to determine the role of HLA Abs in allograft rejection, but consideration of immune responses to non-HLA antigens (including tissue-restricted self-antigens) is still a new territory. Many recent studies have suggested that tissue-restricted self-antigens direct immune responses and play a meaningful role in allograft rejection. Nevertheless, it remains unclear how these tissue-restricted immune responses initiate and perpetuate graft rejection, how tolerance to these tissue-restricted self-antigens are broken, and what role alloimmunity plays in the pathogenesis of chronic rejection despite immunosuppressive regimens.

Current work would suggest a crosstalk between allo- and autoimmunity in both lung and islet transplantation. It is possible that, once initiated, immune responses to tissue-restricted self-antigens are not suppressed by the immunosuppressive regimen, and this smoldering immune reaction contributes to

\section{REFERENCES}

1. Kessler L, Bakopoulou S, Kessler R, Massard G, Santelmo N, Greget M, et al. Combined pancreatic islet-lung transplantation: a novel approach to the treatment of end-stage cystic fibrosis. Am J Transplant (2010) 10(7):1707-12. doi:10.1111/j.1600-6143.2010.03143.x

2. Dellgren C, Nehlin JO, Barington T. Cell surface expression level variation between two common human leukocyte antigen alleles, HLA-A2 and HLAB8, is dependent on the structure of the C terminal part of the alpha 2 and the alpha 3 domains. PLoS One (2015) 10(8):e0135385. doi:10.1371/journal. pone. 0135385

3. Guillaudeux T, Janer M, Wong GK, Spies T, Geraghty DE. The complete genomic sequence of $424,015 \mathrm{bp}$ at the centromeric end of the HLA class I region: gene content and polymorphism. Proc Natl Acad Sci U S A (1998) 95(16):9494-9. doi:10.1073/pnas.95.16.9494

4. Janer M, Geraghty DE. The human major histocompatibility complex: 42,221 bp of genomic sequence, high-density sequence-tagged site map, evolution, and polymorphism for HLA class I. Genomics (1998) 51(1):35-44. doi:10.1006/geno.1998.5377

5. Shiina T, Hosomichi K, Inoko H, Kulski JK. The HLA genomic loci map: expression, interaction, diversity and disease. J Hum Genet (2009) 54(1):15-39. doi:10.1038/jhg.2008.5

6. Robinson J, Halliwell JA, Hayhurst JD, Flicek P, Parham P, Marsh SG. The IPD and IMGT/HLA database: allele variant databases. Nucleic Acids Res (2015) 43(Database issue):D423-31. doi:10.1093/nar/gku1161

7. Gorer PA. Some recent work on tumor immunity. Adv Cancer Res (1956) 4:149-86. doi:10.1016/S0065-230X(08)60724-1

8. Morris PJ, Williams GM, Hume DM, Mickey MR, Terasaki PI. Serotyping for homotransplantation. XII. Occurrence of cytotoxic antibodies following kidney transplantation in man. Transplantation (1968) 6(3):392-9. doi:10.1097/00007890-196805000-00010

9. Patel R, Terasaki PI. Significance of the positive crossmatch test in kidney transplantation. N Engl J Med (1969) 280(14):735-9. doi:10.1056/ NEJM196904032801401

10. Terasaki PI, Cai J. Human leukocyte antigen antibodies and chronic rejection: from association to causation. Transplantation (2008) 86(3):377-83. doi:10.1097/TP.0b013e31817c4cb8 the onset and progression of chronic allograft dysfunction. In experimental models, there is evidence that Abs to both MHC and to tissue-restricted self-antigens can break established tolerance, suggesting that Abs are the driving force in the induction of chronic allograft dysfunction. Therefore, there is an urgent need to develop new diagnostic and/or therapeutic approaches to prevent Abs and to treat chronic allograft dysfunction.

\section{AUTHOR CONTRIBUTIONS}

DKN, PBS, BN, and TM conceptualized the review; DKN and PBS wrote the manuscript; SB participated in discussion; BN and TM critically revised the manuscript.

\section{ACKNOWLEDGMENTS}

We thank Clare Prendergast and Billie Glasscock for editorial assistance in preparing the manuscript.

\section{FUNDING}

The work was supported by funding support from National Institutes of Health to TM (R01HL056643 and R01HL092514) and institutional support by the Baylor Health Care System Foundation to BN.

11. Palmer SM, Davis RD, Hadjiliadis D, Hertz MI, Howell DN, Ward FE, et al. Development of an antibody specific to major histocompatibility antigens detectable by flow cytometry after lung transplant is associated with bronchiolitis obliterans syndrome. Transplantation (2002) 74(6):799-804. doi:10.1097/00007890-200209270-00011

12. Schulman LL, Ho EK, Reed EF, McGregor C, Smith CR, Rose EA, et al. Immunologic monitoring in lung allograft recipients. Transplantation (1996) 61(2):252-7. doi:10.1097/00007890-199601270-00016

13. Kroshus TJ, Kshettry VR, Savik K, John R, Hertz MI, Bolman RM III. Risk factors for the development of bronchiolitis obliterans syndrome after lung transplantation. J Thorac Cardiovasc Surg (1997) 114(2):195-202. doi:10.1016/S0022-5223(97)70144-2

14. Sundaresan S, Mohanakumar T, Smith MA, Trulock EP, Lynch J, Phelan D, et al. HLA-A locus mismatches and development of antibodies to HLA after lung transplantation correlate with the development of bronchiolitis obliterans syndrome. Transplantation (1998) 65(5):648-53. doi:10.1097/00007890-199803150-00008

15. Jaramillo A, Smith MA, Phelan D, Sundaresan S, Trulock EP, Lynch JP, et al. Development of ELISA-detected anti-HLA antibodies precedes the development of bronchiolitis obliterans syndrome and correlates with progressive decline in pulmonary function after lung transplantation. Transplantation (1999) 67(8):1155-61. doi:10.1097/00007890-199904270-00012

16. Girnita AL, McCurry KR, Iacono AT, Duquesnoy R, Corcoran TE, Awad M, et al. HLA-specific antibodies are associated with high-grade and persistent-recurrent lung allograft acute rejection. J Heart Lung Transplant (2004) 23(10):1135-41. doi:10.1016/j.healun.2003.08.030

17. Girnita AL, Duquesnoy R, Yousem SA, Iacono AT, Corcoran TE, Buzoianu M, et al. HLA-specific antibodies are risk factors for lymphocytic bronchiolitis and chronic lung allograft dysfunction. Am J Transplant (2005) 5(1):131-8. doi:10.1111/j.1600-6143.2004.00650.x

18. Jaramillo A, Fernandez FG, Kuo EY, Trulock EP, Patterson GA, Mohanakumar T. Immune mechanisms in the pathogenesis of bronchiolitis obliterans syndrome after lung transplantation. Pediatr Transplant (2005) 9(1):84-93. doi:10.1111/j.1399-3046.2004.00270.x

19. Morrell MR, Pilewski JM, Gries CJ, Pipeling MR, Crespo MM, Ensor $\mathrm{CR}$, et al. De novo donor-specific HLA antibodies are associated with early and high-grade bronchiolitis obliterans syndrome and death after 
lung transplantation. J Heart Lung Transplant (2014) 33(12):1288-94. doi:10.1016/j.healun.2014.07.018

20. Tikkanen JM, Singer LG, Kim SJ, Li Y, Binnie M, Chaparro C, et al. De novo DQ-donor-specific antibodies are associated with chronic lung allograft dysfunction after lung transplantation. Am J Respir Crit Care Med (2016) 194(5):596-606. doi:10.1164/rccm.201509-1857OC

21. Hayes D Jr, Black SM, Tobias JD, Kopp BT, Kirkby SE, Mansour HM, et al. Influence of human leukocyte antigen mismatching on bronchiolitis obliterans syndrome in lung transplantation. J Heart Lung Transplant (2016) 35(2):186-94. doi:10.1016/j.healun.2015.08.022

22. Fukami N, Ramachandran S, Saini D, Walter M, Chapman W, Patterson GA, et al. Antibodies to MHC class I induce autoimmunity: role in the pathogenesis of chronic rejection. J Immunol (2009) 182(1):309-18. doi:10.4049/ jimmunol.182.1.309

23. Takenaka M, Tiriveedhi V, Subramanian V, Hoshinaga K, Patterson AG, Mohanakumar T. Antibodies to MHC class II molecules induce autoimmunity: critical role for macrophages in the immunopathogenesis of obliterative airway disease. PLoS One (2012) 7(8):e42370. doi:10.1371/journal. pone. 0042370

24. Bharat A, Kuo E, Steward N, Aloush A, Hachem R, Trulock EP, et al. Immunological link between primary graft dysfunction and chronic lung allograft rejection. Ann Thorac Surg (2008) 86(1):189-195;discussion196-187. doi:10.1016/j.athoracsur.2008.03.073

25. Hachem RR, Yusen RD, Meyers BF, Aloush AA, Mohanakumar T, Patterson GA, et al. Anti-human leukocyte antigen antibodies and preemptive antibody-directed therapy after lung transplantation. J Heart Lung Transplant (2010) 29(9):973-80. doi:10.1016/j.healun.2010.05.006

26. Saini D, Weber J, Ramachandran S, Phelan D, Tiriveedhi V, Liu M, et al. Alloimmunity-induced autoimmunity as a potential mechanism in the pathogenesis of chronic rejection of human lung allografts. J Heart Lung Transplant (2011) 30(6):624-31. doi:10.1016/j.healun.2011.01.708

27. Ius F, Sommer W, Tudorache I, Kuhn C, Avsar M, Siemeni T, et al. Early donor-specific antibodies in lung transplantation: risk factors and impact on survival. J Heart Lung Transplant (2014) 33(12):1255-63. doi:10.1016/ j.healun.2014.06.015

28. Safavi S, Robinson DR, Soresi S, Carby M, Smith JD. De novo donor HLAspecific antibodies predict development of bronchiolitis obliterans syndrome after lung transplantation. J Heart Lung Transplant (2014) 33(12):1273-81. doi:10.1016/j.healun.2014.07.012

29. Seetharam A, Tiriveedhi V, Mohanakumar T. Alloimmunity and autoimmunity in chronic rejection. Curr Opin Organ Transplant (2010) 15(4):531-6. doi:10.1097/MOT.0b013e32833b31f4

30. Angaswamy N, Saini D, Ramachandran S, Nath DS, Phelan D, Hachem $\mathrm{R}$, et al. Development of antibodies to human leukocyte antigen precedes development of antibodies to major histocompatibility class I-related chain A and are significantly associated with development of chronic rejection after human lung transplantation. Hum Immunol (2010) 71(6):560-5. doi:10.1016/j.humimm.2010.02.021

31. Goers TA, Ramachandran S, Aloush A, Trulock E, Patterson GA, Mohanakumar T. De novo production of K-alpha1 tubulin-specific antibodies: role in chronic lung allograft rejection. J Immunol (2008) 180(7):4487-94. doi:10.4049/jimmunol.180.7.4487

32. Iwata T, Philipovskiy A, Fisher AJ, Presson RG Jr, Chiyo M, Lee J, et al. Antitype $\mathrm{V}$ collagen humoral immunity in lung transplant primary graft dysfunction. J Immunol (2008) 181(8):5738-47. doi:10.4049/jimmunol.181.8.5738

33. Bharat A, Saini D, Steward N, Hachem R, Trulock EP, Patterson GA, et al. Antibodies to self-antigens predispose to primary lung allograft dysfunction and chronic rejection. Ann Thorac Surg (2010) 90(4):1094-101. doi:10.1016/ j.athoracsur.2010.06.009

34. Witt CA, Gaut JP, Yusen RD, Byers DE, Iuppa JA, Bennett Bain K, et al. Acute antibody-mediated rejection after lung transplantation. J Heart Lung Transplant (2013) 32(10):1034-40. doi:10.1016/j.healun.2013.07.004

35. Hachem RR, Tiriveedhi V, Patterson GA, Aloush A, TrulockEP, Mohanakumar T. Antibodies to K-alpha 1 tubulin and collagen V are associated with chronic rejection after lung transplantation. Am J Transplant (2012) 12(8):2164-71. doi:10.1111/j.1600-6143.2012.04079.x

36. Subramanian V, Ramachandran S, Banan B, Bharat A, Wang X, Benshoff $\mathrm{N}$, et al. Immune response to tissue-restricted self-antigens induces airway inflammation and fibrosis following murine lung transplantation. Am J Transplant (2014) 14(10):2359-66. doi:10.1111/ajt.12908

37. Terasaki PI. Humoral theory of transplantation. Am J Transplant (2003) 3(6):665-73. doi:10.1034/j.1600-6143.2003.00135.x

38. Terasaki PI, Cai J. Humoral theory of transplantation: further evidence. Curr Opin Immunol (2005) 17(5):541-5. doi:10.1016/j.coi.2005.07.018

39. Benichou G, Takizawa PA, Olson CA, McMillan M, Sercarz EE. Donor major histocompatibility complex (MHC) peptides are presented by recipient MHC molecules during graft rejection. JExp Med (1992) 175(1):305-8. doi:10.1084/jem.175.1.305

40. Smyth LA, Herrera OB, Golshayan D, Lombardi G, Lechler RI. A novel pathway of antigen presentation by dendritic and endothelial cells: Implications for allorecognition and infectious diseases. Transplantation (2006) 82(1 Suppl):S15-8. doi:10.1097/01.tp.0000231347.06149.ca

41. Sun M, Chen S, Adams SM, Florer JB, Liu H, Kao WW, et al. Collagen $\mathrm{V}$ is a dominant regulator of collagen fibrillogenesis: dysfunctional regulation of structure and function in a corneal-stroma-specific Col5a1null mouse model. JCell Sci (2011) 124(Pt 23):4096-105. doi:10.1242/ jcs. 091363

42. Yoshida S, Iwata T, Chiyo M, Smith GN, Foresman BH, Mickler EA, et al. Metalloproteinase inhibition has differential effects on alloimmunity, autoimmunity, and histopathology in the transplanted lung. Transplantation (2007) 83(6):799-808. doi:10.1097/01.tp.0000258600.05531.5d

43. Iwata T, Chiyo M, Yoshida S, Smith GN Jr, Mickler EA, Presson R Jr, et al. Lung transplant ischemia reperfusion injury: metalloprotease inhibition down-regulates exposure of type $\mathrm{V}$ collagen, growth-related oncogene-induced neutrophil chemotaxis, and tumor necrosis factor-alpha expression. Transplantation (2008) 85(3):417-26. doi:10.1097/TP.0b013e31815e91b6

44. Haque MA, Mizobuchi T, Yasufuku K, Fujisawa T, Brutkiewicz RR, Zheng $\mathrm{Y}$, et al. Evidence for immune responses to a self-antigen in lung transplantation: role of type $\mathrm{V}$ collagen-specific $\mathrm{T}$ cells in the pathogenesis of lung allograft rejection. J Immunol (2002) 169(3):1542-9. doi:10.4049/ jimmunol.169.3.1542

45. Braun RK, Molitor-Dart M, Wigfield C, Xiang Z, Fain SB, Jankowska-Gan E, et al. Transfer of tolerance to collagen type V suppresses T-helper-cell-17 lymphocyte-mediated acute lung transplant rejection. Transplantation (2009) 88(12):1341-8. doi:10.1097/TP.0b013e3181bcde7b

46. Yasufuku K, Heidler KM, O’Donnell PW, Smith GN Jr, Cummings OW, Foresman $\mathrm{BH}$, et al. Oral tolerance induction by type $\mathrm{V}$ collagen downregulates lung allograft rejection. Am J Respir Cell Mol Biol (2001) 25(1):26-34. doi:10.1165/ajrcmb.25.1.4431

47. Yasufuku K, Heidler KM, Woods KA, Smith GN Jr, Cummings OW, Fujisawa T, et al. Prevention of bronchiolitis obliterans in rat lung allografts by type V collagen-induced oral tolerance. Transplantation (2002) 73(4):500-5. doi:10.1097/00007890-200202270-00002

48. Eguiluz-Gracia I, Schultz HH, Sikkeland LI, Danilova E, Holm AM, Pronk CJ, et al. Long-term persistence of human donor alveolar macrophages in lung transplant recipients. Thorax (2016) 71(11):1006-11. doi:10.1136/ thoraxjnl-2016-208292

49. Nayak DK, Zhou F, Xu M, Huang J, Tsuji M, Hachem R, et al. Long-term persistence of donor alveolar macrophages in human lung transplant recipients that influences donor-specific immune responses. Am J Transplant (2016) 16(8):2300-11. doi:10.1111/ajt.13819

50. Gunasekaran M, Xu Z, Nayak DK, Sharma M, Hachem R, Walia R, et al. Donor-derived exosomes with lung self-antigens in human lung allograft rejection. Am J Transplant (2016). doi:10.1111/ajt.13915

51. Liu Q, Rojas-Canales DM, Divito SJ, Shufesky WJ, Stolz DB, Erdos G, et al. Donor dendritic cell-derived exosomes promote allograft-targeting immune response. J Clin Invest (2016) 126(8):2805-20. doi:10.1172/JCI84577

52. Roman J, Ritzenthaler JD, Perez RL, Roser SL. Differential modes of regulation of interleukin-1beta expression by extracellular matrices. Immunology (1999) 98(2):228-37. doi:10.1046/j.1365-2567.1999.00866.x

53. Muro AF, Chauhan AK, Gajovic S, Iaconcig A, Porro F, Stanta G, et al. Regulated splicing of the fibronectin EDA exon is essential for proper skin wound healing and normal lifespan. J Cell Biol (2003) 162(1):149-60. doi: $10.1083 /$ jcb. 200212079

54. Watson WH, Ritzenthaler JD, Roman J. Lung extracellular matrix and redox regulation. Redox Biol (2016) 8:305-15. doi:10.1016/j.redox.2016.02.005 
55. Smith SM, Zhang G, Birk DE. Collagen V localizes to pericellular sites during tendon collagen fibrillogenesis. Matrix Biol (2014) 33:47-53. doi:10.1016/ j.matbio.2013.08.003

56. Harrod KS, Mounday AD, Stripp BR, Whitsett JA. Clara cell secretory protein decreases lung inflammation after acute virus infection. Am J Physiol (1998) 275(5 Pt 1):L924-30.

57. Wang SZ, Rosenberger CL, Bao YX, Stark JM, Harrod KS. Clara cell secretory protein modulates lung inflammatory and immune responses to respiratory syncytial virus infection. J Immunol (2003) 171(2):1051-60. doi:10.4049/ jimmunol.171.2.1051

58. Elizur A, Adair-Kirk TL, Kelley DG, Griffin GL, deMello DE, Senior RM. Clara cells impact the pulmonary innate immune response to LPS. Am J Physiol Lung Cell Mol Physiol (2007) 293(2):L383-92. doi:10.1152/ ajplung.00024.2007

59. Tomita T, Sakurai Y, Ishibashi S, Maru Y. Imbalance of clara cell-mediated homeostatic inflammation is involved in lung metastasis. Oncogene (2011) 30(31):3429-39. doi:10.1038/onc.2011.53

60. Kurowski M, Jurczyk J, Jarzebska M, Moskwa S, Makowska JS, Krysztofiak H, et al. Association of serum clara cell protein CC16 with respiratory infections and immune response to respiratory pathogens in elite athletes. Respir Res (2014) 15:45. doi:10.1186/1465-9921-15-45

61. Kelly FL, Kennedy VE, Jain R, Sindhwani NS, Finlen Copeland CA, Snyder LD, et al. Epithelial clara cell injury occurs in bronchiolitis obliterans syndrome after human lung transplantation. Am J Transplant (2012) 12(11):3076-84. doi:10.1111/j.1600-6143.2012.04201.x

62. Levine DJ, Glanville AR, Aboyoun C, Belperio J, Benden C, Berry GJ, et al. Antibody-mediated rejection of the lung: a consensus report of the International Society for Heart and Lung Transplantation. J Heart Lung Transplant (2016) 35(4):397-406. doi:10.1016/j.healun.2016.01.1223

63. Masson E, Stern M, Chabod J, Thevenin C, Gonin F, Rebibou JM, et al. Hyperacute rejection after lung transplantation caused by undetected low-titer anti-HLA antibodies. J Heart Lung Transplant (2007) 26(6):642-5. doi:10.1016/j.healun.2007.03.007

64. Bharat A, Chiu S, Zheng Z, Sun H, Yeldandi A, DeCamp MM, et al. Lung-restricted antibodies mediate primary graft dysfunction and prevent allo-tolerance following murine lung transplantation. Am J Respir Cell Mol Biol (2016) 55(4):532-41. doi:10.1165/rcmb.2016-0077OC

65. Martinu T, Chen DF, Palmer SM. Acute rejection and humoral sensitization in lung transplant recipients. Proc Am Thorac Soc (2009) 6(1):54-65. doi:10.1513/pats.200808-080GO

66. Martinu T, Howell DN, Palmer SM. Acute cellular rejection and humoral sensitization in lung transplant recipients. Semin Respir Crit Care Med (2010) 31(2):179-88. doi:10.1055/s-0030-1249113

67. Lobo LJ, Aris RM, Schmitz J, Neuringer IP. Donor-specific antibodies are associated with antibody-mediated rejection, acute cellular rejection, bronchiolitis obliterans syndrome, and cystic fibrosis after lung transplantation. J Heart Lung Transplant (2013) 32(1):70-7. doi:10.1016/j.healun.2012.10.007

68. Jindra PT, Jin YP, Rozengurt E, Reed EF. HLA class I antibody-mediated endothelial cell proliferation via the mTOR pathway. JImmunol (2008) 180(4):2357-66. doi:10.4049/jimmunol.180.4.2357

69. Todd JL, Palmer SM. Bronchiolitis obliterans syndrome: the final frontier for lung transplantation. Chest (2011) 140(2):502-8. doi:10.1378/chest.10-2838

70. Meyer KC, Raghu G, Verleden GM, Corris PA, Aurora P, Wilson KC, et al. An international ISHLT/ATS/ERS clinical practice guideline: diagnosis and management of bronchiolitis obliterans syndrome. Eur Respir J (2014) 44(6):1479-503. doi:10.1183/09031936.00107514

71. Sharples LD, McNeil K, Stewart S, Wallwork J. Risk factors for bronchiolitis obliterans: a systematic review of recent publications. J Heart Lung Transplant (2002) 21(2):271-81. doi:10.1016/S1053-2498(01)00360-6

72. Verleden GM, Raghu G, Meyer KC, Glanville AR, Corris P. A new classification system for chronic lung allograft dysfunction. J Heart Lung Transplant (2014) 33(2):127-33. doi:10.1016/j.healun.2013.10.022

73. Verleden SE, Ruttens D, Vandermeulen E, Bellon H, Van Raemdonck DE, Dupont LJ, et al. Restrictive chronic lung allograft dysfunction: where are we now? J Heart Lung Transplant (2015) 34(5):625-30. doi:10.1016/ j.healun.2014.11.007

74. Verleden SE, Vasilescu DM, McDonough JE, Ruttens D, Vos R, Vandermeulen E, et al. Linking clinical phenotypes of chronic lung allograft dysfunction to changes in lung structure. Eur Respir J (2015) 46(5):1430-9. doi:10.1183/09031936.00010615

75. Verleden SE, Ruttens D, Vandermeulen E, Bellon H, Dubbeldam A, De Wever $\mathrm{W}$, et al. Predictors of survival in restrictive chronic lung allograft dysfunction after lung transplantation. J Heart Lung Transplant (2016) 35(9):1078-84. doi:10.1016/j.healun.2016.03.022

76. Verleden SE, Sacreas A, Vos R, Vanaudenaerde BM, Verleden GM. Advances in understanding bronchiolitis obliterans after lung transplantation. Chest (2016) 150(1):219-25. doi:10.1016/j.chest.2016.04.014

77. Weber DJ, Wilkes DS. The role of autoimmunity in obliterative bronchiolitis after lung transplantation. Am J Physiol Lung Cell Mol Physiol (2013) 304(5):L307-11. doi:10.1152/ajplung.00378.2012

78. Baskaran G, Tiriveedhi V, Ramachandran S, Aloush A, Grossman B, Hachem R, et al. Efficacy of extracorporeal photopheresis in clearance of antibodies to donor-specific and lung-specific antigens in lung transplant recipients. J Heart Lung Transplant (2014) 33(9):950-6. doi:10.1016/ j.healun.2014.04.020

79. Ius F, Sommer W, Tudorache I, Kuhn C, Avsar M, Siemeni T, et al. Preemptive treatment with therapeutic plasma exchange and rituximab for early donor-specific antibodies after lung transplantation. J Heart Lung Transplant (2015) 34(1):50-8. doi:10.1016/j.healun.2014.09.019

80. Tinckam KJ, Keshavjee S, Chaparro C, Barth D, Azad S, Binnie M, et al. Survival in sensitized lung transplant recipients with perioperative desensitization. Am J Transplant (2015) 15(2):417-26. doi:10.1111/ajt.13076

81. Tiriveedhi V, Gautam B, Sarma NJ, Askar M, Budev M, Aloush A, et al. Pretransplant antibodies to Kalphal tubulin and collagen- $\mathrm{V}$ in lung transplantation: clinical correlations. J Heart Lung Transplant (2013) 32(8):807-14. doi:10.1016/j.healun.2013.01.187

82. Tait BD, Susal C, Gebel HM, Nickerson PW, Zachary AA, Claas FH, et al. Consensus guidelines on the testing and clinical management issues associated with HLA and non-HLA antibodies in transplantation. Transplantation (2013) 95(1):19-47. doi:10.1097/TP.0b013e31827a19cc

83. Fuller TC, Phelan D, Gebel HM, Rodey GE. Antigenic specificity of antibody reactive in the antiglobulin-augmented lymphocytotoxicity test. Transplantation (1982) 34(1):24-9. doi:10.1097/00007890-19820700000005

84. Hagedorn PH, Burton CM, Carlsen J, Steinbruchel D, Andersen CB, Sahar E, et al. Chronic rejection of a lung transplant is characterized by a profile of specific autoantibodies. Immunology (2010) 130(3):427-35. doi:10.1111/j.1365-2567.2010.03246.x

85. Hering BJ, Clarke WR, Bridges ND, Eggerman TL, Alejandro R, Bellin $\mathrm{MD}$, et al. Phase 3 trial of transplantation of human islets in type 1 diabetes complicated by severe hypoglycemia. Diabetes Care (2016) 39(7):1230-40. doi:10.2337/dc15-1988

86. Markmann JF, Deng S, Huang X, Desai NM, Velidedeoglu EH, Lui C, et al. Insulin independence following isolated islet transplantation and single islet infusions. Ann Surg (2003) 237(6):741-9. doi:10.1097/00000658-20030600000001; discussion 749-750,

87. Shapiro AM, Ricordi C, Hering BJ, Auchincloss H, Lindblad R, Robertson RP, et al. International trial of the Edmonton protocol for islet transplantation. N Engl J Med (2006) 355(13):1318-30. doi:10.1056/NEJMoa061267

88. Naziruddin B, Wease S, Stablein D, Barton FB, Berney T, Rickels MR, et al. HLA class I sensitization in islet transplant recipients: report from the Collaborative Islet Transplant Registry. Cell Transplant (2012) 21(5):901-8. doi:10.3727/096368911X612468

89. Brooks AM, Carter V, Liew A, Marshall H, Aldibbiat A, Sheerin NS, et al. De novo donor-specific HLA antibodies are associated with rapid loss of graft function following islet transplantation in type 1 diabetes. Am J Transplant (2015) 15(12):3239-46. doi:10.1111/ajt.13407

90. Chaigne B, Geneugelijk K, Bedat B, Ahmed MA, Honger G, de Seigneux S, et al. Immunogenicity of anti-HLA antibodies in pancreas and islet transplantation. Cell Transplant (2016). doi:10.3727/096368916X691673

91. Jackson AM, Connolly JE, Matsumoto S, Noguchi H, Onaca N, Levy MF, et al. Evidence for induced expression of HLA class II on human islets: possible mechanism for HLA sensitization in transplant recipients. Transplantation (2009) 87(4):500-6. doi:10.1097/TP.0b013e318195fc33

92. Mohanakumar T, Narayanan K, Desai N, Ramachandran S, Shenoy S, Jendrisak $M$, et al. A significant role for histocompatibility in human 
islet transplantation. Transplantation (2006) 82(2):180-7. doi:10.1097/ 01.tp.0000226161.82581.b2

93. Rickels MR, Kearns J, Markmann E, Palanjian M, Markmann JF, Naji A, et al. HLA sensitization in islet transplantation. Clin Transpl (2006):413-20.

94. Cardani R, Pileggi A, Ricordi C, Gomez C, Baidal DA, Ponte GG, et al. Allosensitization of islet allograft recipients. Transplantation (2007) 84(11):1413-27. doi:10.1097/01.tp.0000290388.70019.6e

95. Campbell PM, Senior PA, Salam A, Labranche K, Bigam DL, Kneteman $\mathrm{NM}$, et al. High risk of sensitization after failed islet transplantation. Am J Transplant (2007) 7(10):2311-7. doi:10.1111/j.1600-6143.2007.01923.x

96. Piemonti L, Everly MJ, Maffi P, Scavini M, Poli F, Nano R, et al. Alloantibody and autoantibody monitoring predicts islet transplantation outcome in human type 1 diabetes. Diabetes (2013) 62(5):1656-64. doi:10.2337/ db12-1258

97. Bittscheidt $\mathrm{H}$, Bektas $\mathrm{H}$, Winkler $\mathrm{M}$, Klempnauer J. Impact of donorrecipient MHC matching on experimental islet allotransplant survival in naive and presensitized Lewis rats. Transplantation (2004) 78(1):162-4. doi:10.1097/01.TP.0000133539.74599.0B

98. Hilbrands R, Huurman VA, Gillard P, Velthuis JH, De Waele M, Mathieu C, et al. Differences in baseline lymphocyte counts and autoreactivity are associated with differences in outcome of islet cell transplantation in type 1 diabetic patients. Diabetes (2009) 58(10):2267-76. doi:10.2337/ $\mathrm{db} 09-0160$

99. Roelen DL, Huurman VA, Hilbrands R, Gillard P, Duinkerken G, van der Meer-Prins PW, et al. Relevance of cytotoxic alloreactivity under different immunosuppressive regimens in clinical islet cell transplantation. Clin Exp Immunol (2009) 156(1):141-8. doi:10.1111/j.1365-2249.2008. 03812.x

100. Campbell PM, Salam A, Ryan EA, Senior P, Paty BW, Bigam D, et al. Pretransplant HLA antibodies are associated with reduced graft survival after clinical islet transplantation. Am J Transplant (2007) 7(5):1242-8. doi:10.1111/j.1600-6143.2007.01777.x

101. Bouwman LH, Ling Z, Duinkerken G, Pipeleers DG, Roep BO. HLA incompatibility and immunogenicity of human pancreatic islet preparations cocultured with blood cells of healthy donors. Hum Immunol (2005) 66(5):494-500. doi:10.1016/j.humimm.2005.01.018

102. Monti P, Vignali D, Piemonti L. Monitoring inflammation, humoral and cell-mediated immunity in pancreas and islet transplants. Curr Diabetes Rev (2015) 11(3):135-43. doi:10.2174/1573399811666150317125820

103. Vendrame F, Pileggi A, Laughlin E, Allende G, Martin-Pagola A, Molano $\mathrm{RD}$, et al. Recurrence of type 1 diabetes after simultaneous pancreas-kidney transplantation, despite immunosuppression, is associated with autoantibodies and pathogenic autoreactive CD4 T-cells. Diabetes (2010) 59(4):947-57. doi:10.2337/db09-0498

104. Jaeger C, Brendel MD, Hering BJ, Eckhard M, Bretzel RG. Progressive islet graft failure occurs significantly earlier in autoantibody-positive than in autoantibody-negative IDDM recipients of intrahepatic islet allografts. Diabetes (1997) 46(11):1907-10. doi:10.2337/diabetes.46.11.1907

105. Occhipinti M, Lampasona V, Vistoli F, Bazzigaluppi E, Scavini M, Boggi U, et al. Zinc transporter 8 autoantibodies increase the predictive value of islet autoantibodies for function loss of technically successful solitary pancreas transplant. Transplantation (2011) 92(6):674-7. doi:10.1097/ TP.0b013e31822ae65f

106. Roep BO, Stobbe I, Duinkerken G, van Rood JJ, Lernmark A, Keymeulen B, et al. Auto- and alloimmune reactivity to human islet allografts transplanted into type 1 diabetic patients. Diabetes (1999) 48(3):484-90. doi:10.2337/ diabetes.48.3.484

107. Huurman VA, Hilbrands R, Pinkse GG, Gillard P, Duinkerken G, van de Linde $\mathrm{P}$, et al. Cellular islet autoimmunity associates with clinical outcome of islet cell transplantation. PLoS One (2008) 3(6):e2435. doi:10.1371/journal. pone. 0002435

108. Chujo D, Foucat E, Takita M, Itoh T, Sugimoto K, Shimoda M, et al. Emergence of a broad repertoire of GAD65-specific T-cells in type 1 diabetes patients with graft dysfunction after allogeneic islet transplantation. Cell Transplant (2012) 21(12):2783-95. doi:10.3727/096368912X654993

109. Monti P, Scirpoli M, Maffi P, Ghidoli N, De Taddeo F, Bertuzzi F, et al. Islet transplantation in patients with autoimmune diabetes induces homeostatic cytokines that expand autoreactive memory T cells. J Clin Invest (2008) 118(5):1806-14. doi:10.1172/JCI35197

110. Huurman VA, Velthuis JH, Hilbrands R, Tree TI, Gillard P, van der MeerPrins PM, et al. Allograft-specific cytokine profiles associate with clinical outcome after islet cell transplantation. Am J Transplant (2009) 9(2):382-8. doi:10.1111/j.1600-6143.2008.02479.x

111. Velthuis JH, Unger WW, Abreu JR, Duinkerken G, Franken K, Peakman M, et al. Simultaneous detection of circulating autoreactive CD8+ T-cells specific for different islet cell-associated epitopes using combinatorial MHC multimers. Diabetes (2010) 59(7):1721-30. doi:10.2337/db09-1486

112. Andersson A, Borg H, Hallberg A, Hellerstrom C, Sandler S, Schnell A. Long-term effects of cyclosporin A on cultured mouse pancreatic islets. Diabetologia (1984) 27(Suppl):66-9. doi:10.1007/BF00275649

113. Ranta F, Avram D, Berchtold S, Dufer M, Drews G, Lang F, et al. Dexamethasone induces cell death in insulin-secreting cells, an effect reversed by exendin- 4 . Diabetes (2006) 55(5):1380-90. doi:10.2337/db05-1220

114. Mineo D, Sageshima J, Burke GW, Ricordi C. Minimization and withdrawal of steroids in pancreas and islet transplantation. Transpl Int (2009) 22(1):20-37. doi:10.1111/j.1432-2277.2008.00761.x

115. Nielsen JH, Mandrup-Poulsen T, Nerup J. Direct effects of cyclosporin A on human pancreatic beta-cells. Diabetes (1986) 35(9):1049-52. doi:10.2337/ diab.35.9.1049

116. Robertson RP. Cyclosporin-induced inhibition of insulin secretion in isolated rat islets and HIT cells. Diabetes (1986) 35(9):1016-9. doi:10.2337/ diab.35.9.1016

117. Shapiro AM, Lakey JR, Ryan EA, Korbutt GS, Toth E, Warnock GL, et al. Islet transplantation in seven patients with type 1 diabetes mellitus using a glucocorticoid-free immunosuppressive regimen. N Engl J Med (2000) 343(4):230-8. doi:10.1056/NEJM200007273430401

118. Zhang N, Su D, Qu S, Tse T, Bottino R, Balamurugan AN, et al. Sirolimus is associated with reduced islet engraftment and impaired beta-cell function. Diabetes (2006) 55(9):2429-36. doi:10.2337/db06-0173

119. Niclauss N, Bosco D, Morel P, Giovannoni L, Berney T, Parnaud G. Rapamycin impairs proliferation of transplanted islet beta cells. Transplantation (2011) 91(7):714-22. doi:10.1097/TP.0b013e31820c10c8

120. Melzi R, Maffi P, Nano R, Sordi V, Mercalli A, Scavini M, et al. Rapamycin does not adversely affect intrahepatic islet engraftment in mice and improves early islet engraftment in humans. Islets (2009) 1(1):42-9. doi:10.4161/ isl.1.1.8881

121. Yoshimura N, Matsui S, Hamashima T, Oka T. Effect of a new immunosuppressive agent, FK506, on human lymphocyte responses in vitro. II. Inhibition of the production of IL-2 and gamma-IFN, but not B cell-stimulating factor 2 . Transplantation(1989)47(2):356-9.doi:10.1097/00007890-198902000-00035

122. Ryan EA, Paty BW, Senior PA, Bigam D, Alfadhli E, Kneteman NM, et al. Five-year follow-up after clinical islet transplantation. Diabetes (2005) 54(7):2060-9. doi:10.2337/diabetes.54.7.2060

123. Barton FB, Rickels MR, Alejandro R, Hering BJ, Wease S, Naziruddin B, et al. Improvement in outcomes of clinical islet transplantation: 1999-2010. Diabetes Care (2012) 35(7):1436-45. doi:10.2337/dc12-0063

124. Bellin MD, Barton FB, Heitman A, Harmon JV, Kandaswamy R, Balamurugan $\mathrm{AN}$, et al. Potent induction immunotherapy promotes long-term insulin independence after islet transplantation in type 1 diabetes. Am J Transplant (2012) 12(6):1576-83. doi:10.1111/j.1600-6143.2011.03977.x

125. Posselt AM, Szot GL, Frassetto LA, Masharani U, Tavakol M, Amin R, et al Islet transplantation in type 1 diabetic patients using calcineurin inhibitor-free immunosuppressive protocols based on T-cell adhesion or costimulation blockade. Transplantation (2010) 90(12):1595-601. doi:10.1097/ TP.0b013e3181fe1377

126. Matsumoto S, Takita M, Chaussabel D, Noguchi H, Shimoda M, Sugimoto K, et al. Improving efficacy of clinical islet transplantation with iodixanol based islet purification, thymoglobulin induction and blockage of IL-1-beta and TNF-alpha. Cell Transplant (2011) 20(10):1641-7. doi:10.3727/0963689 10X564058

127. Maffi P, Berney T, Nano R, Niclauss N, Bosco D, Melzi R, et al. Calcineurin inhibitor-free immunosuppressive regimen in type 1 diabetes patients receiving islet transplantation: single-group phase $1 / 2$ trial. Transplantation (2014) 98(12):1301-9. doi:10.1097/TP.0000000000000396 
128. Gillard P, Rustandi M, Efendi A, Lee da H, Ling Z, Hilbrands R, et al. Early alteration of kidney function in nonuremic type 1 diabetic islet transplant recipients under tacrolimus-mycophenolate therapy. Transplantation (2014) 98(4):451-7. doi:10.1097/TP.0000000000000086

129. Lehmann R, Graziano J, Brockmann J, Pfammatter T, Kron P, de Rougemont $\mathrm{O}$, et al. Glycemic control in simultaneous islet-kidney versus pancreas-kidney transplantation in type 1 diabetes: a prospective 13-year follow-up. Diabetes Care (2015) 38(5):752-9. doi:10.2337/dc14-1686

130. Nilsson B, Ekdahl KN, Korsgren O. Control of instant blood-mediated inflammatory reaction to improve islets of Langerhans engraftment. Curr Opin Organ Transplant (2011) 16(6):620-6. doi:10.1097/MOT.0b013e328 $34 \mathrm{c} 2393$

131. Itoh T, Iwahashi S, Kanak MA, Shimoda M, Takita M, Chujo D, et al. Elevation of high-mobility group box 1 after clinical autologous islet transplantation and its inverse correlation with outcomes. Cell Transplant (2014) 23(2):153-65. doi:10.3727/096368912X658980

Conflict of Interest Statement: The authors declare that the research was conducted in the absence of any commercial or financial relationships that could be construed as a potential conflict of interest.

Copyright (c) 2016 Nayak, Saravanan, Bansal, Naziruddin and Mohanakumar. This is an open-access article distributed under the terms of the Creative Commons Attribution License (CC BY). The use, distribution or reproduction in other forums is permitted, provided the original author(s) or licensor are credited and that the original publication in this journal is cited, in accordance with accepted academic practice. No use, distribution or reproduction is permitted which does not comply with these terms. 